\title{
CRIANÇAS, DISPOSITIVOS MÓVEIS E APRENDIZAGENS FORMAIS E INFORMAISi
}

\begin{tabular}{c} 
CHILDREN, MOBILE DEVICES AND FORMAL AND \\
INFORMAL LEARNING \\
\hline NIÑOS, LOS DISPOSITIVOS MÓVILES Y EL APRENDIZAJE FORMALES \\
Y INFORMALES
\end{tabular}

Mônica Fantin ${ }^{1}$

\section{RESUMO}

As mudanças nos lugares que as crianças ocupam na sociedade, suas formas de socialização e suas práticas lúdicas e culturais contribuem para a construção de novos modos de aprendizagem, cada vez mais mediados pelo uso de dispositivos móveis, que desencadeiam a emergência de novas metodologias e espaços de formação. Nesse sentido, desenvolvemos uma pesquisa qualitativa com crianças sobre as práticas de multiletramentos e aprendizagens formais e informais na cultura digital, a fim de identificar e fortalecer os diálogos entre os contextos escolares e culturais com a aplicação da metodologia dos Episódios de Aprendizagem Situada (EAS). A investigação envolveu observações, intervenções didáticas, entrevistas e grupos focais com crianças de diferentes faixas etárias em duas escolas públicas de Florianópolis, SC/Brasil, entre 2014/2015. Análises parciais revelam que as práticas midiáticas das crianças com dispositivos móveis fora da escola, quando articuladas às propostas mídia-educativas, podem desencadear aprendizagens significativas e deslocar os protagonismos dos dispositivos em busca de novas possibilidades de autoria infantil. Práticas que interpelam os que atuam com educação e thes desafiam a pensar em novas formas de mediação diante dos contornos dessa nova paisagem cultural. Neste texto, discutimos os fundamentos teóricos da relação entre crianças, dispositivos móveis e aprendizagens, a metodologia da pesquisa com o foco na estratégia de aprendizagem learning by doing, algumas narrativas dos episódios e as considerações sobre as práticas dos estudantes com os dispositivos móveis.

PALAVRAS-CHAVE: Crianças. Práticas culturais. Escola. Aprendizagem Situada

\begin{abstract}
The changes in places that children occupy in society, its forms of socialization and its ludical and cultural practices contribute to the construction of new ways of learning, increasingly mediated by the use of mobile devices that trigger the emergence of new methodologies and spaces formation. Accordingly, we developed a qualitative research with children on multiliteracies practices and formal and informal learning in the digital culture in order to identify and strengthen the dialogue between the school and cultural contexts with the application of the methodology of Situated Learning Episodes SLE. The research involved observations, educational interventions, interviews and focus groups with children of different age groups in two public schools in Florianópolis, SC/Brazil, between 2014-2015. Partial analyzes reveal that the media practices of children with mobile devices out of school, when articulated to the media and educational proposals, can trigger significant learning and move the protagonism of the devices for new possibilities of child authorship. Practices that challenge those working with education and challenge to think of new forms of mediation before the contours of this new cultural landscape. In this text we discussed the theoritical framework of the relationship between children, mobile devices and learning, the research methodology focusing in the strategy 'learning by doing', some narratives about the episodes and the considerations on students' practices with mobile devices.
\end{abstract}

\footnotetext{
${ }^{1}$ Doutora em Educação - Universidade Federal de Santa Catarina (UFSC) - Florianópolis, SC. Brasil. Professora Associada - Centro de Educação da Universidade Federal de Santa Catarina (UFSC) - Florianópolis, SC. Brasil. E-mail: mfantin@terra.com.br Submetido em: 14/11/2016 - Aceito em: 04/12/2017
}

(C) ETD-Educação Temática Digital Campinas, SP $\quad$ v.20 $\quad$ n.1 $\quad$ p. $66-80 \quad$ jan./abr. 2018


KEYWORDS: Children. Cultural practices. School. Situated learning.

\section{RESUMEN}

Los cambios en los lugares de los niños en la sociedad, sus formas de socialización y sus prácticas recreativas y culturales contribuyen a la construcción de nuevas formas de aprendizaje, cada vez más mediadas por el uso de dispositivos móviles que desencadenan nuevas metodologías y espacios de formación. En consecuencia, hemos desarrollado una investigación cualitativa con los niños en las prácticas de multialfabetizaciones y el aprendizaje formal e informal en la cultura digital con el fin de identificar y fortalecer el diálogo entre la escuela y los contextos culturales desde la metodología de aprendizaje Episodios de Aprendizaje Situado (EAS). La investigación envolve observaciones participativas, intervenciones educativas, entrevistas y grupos focales con niños de diferentes grupos de edad en dos escuelas públicas en Florianópolis, SC/Brasil, entre 2014-2015. Análisis parciales revelan que las practicas culturales de los niños con dispositivos móviles fuera de la escuela, cuando articuladas con propuestas educativas, pueden desencadenar un aprendizaje significativo y mover el protagonismo de los dispositivos para nuevas posibilidades de autoría del niño. Prácticas que desafían los que trabajan con la educación en el sentido de pensar en nuevas formas de mediación en este nuevo paisaje cultural. En el texto discutimos los fundamentos teóricos de la relación entre los niños, los dispositivos móviles y el aprendizaje, la metodología de la investigación con el foco en la estrategia learning by doing, algunas narrativas y las consideraciones sobre las prácticas de los estudiantes con los dispositivos móviles.

PALABRAS CLAVE: Niños. Prácticas culturales. Escuela. Arendizaje situado.

\section{EPISÓDIOS DE APRENDIZAGEM SITUADA, DISPOSITIVOS MÓVEIS E AS CRIANÇAS}

A vida na condição pós-midiática implica uma reconstrução do sentido das práticas cotidianas, que são atravessadas por três grandes narrativas: a naturalização da tecnologia, a subjetivação da experiência e a socialização dos vínculos relacionais, como enfatiza Eugeni (2015). Nesse processo, observamos profundas transformações, não apenas no uso das mídias e dispositivos mas também "nos modos de entender as relações interpessoais, os estilos comunicativos, os métodos e conteúdos de aprendizagem, sobretudo, o sentido de aprender e da relação educativa" (EUGENI, 2015, p.27).

Nesse quadro, perguntamo-nos sobre o lugar das crianças na sociedade contemporânea e reafirmamos a importância de entender as culturas infantis (SARMENTO; PINTO, 1997) e as formas de participação que reafirmam as crianças como sujeitos de direitos e atores sociais integrados à cultura mais ampla, no contexto das diferentes condições de infância . Na sociedade atual, as formas de socialização, a construcão de conhecimento e a apreensão do mundo , bem como os valores especifí cos das criancas , também se constroem nos diferentes espaços da cultura digital, o que implica pensar nas diferentes formas de consumo e nas interações em redes. Tal processo reafirma a defesa dos direitos das crianças em relação às mídias - os 3 P: Proteção, Provisão e Participação - e desafia as práticas em mídia-educação. 
Diante disso, cultura digital, mídia-educação, multiliteracies e episódios de aprendizagem situados são conceitos importantes para entendermos as crianças hoje. Pesquisas realizadas em diferentes contextos socioculturais (BUCKINGHAM, 2007; COPE;KALANTZIS, 2000;FANTIN 2010, 2015a; LANKSHEAR;KNOBEL, 2011;

PEREIRA;PINTO;MOURA, 2015;RIVOLTELLA, 2013) discutem, a partir de conceitos como media literacy e seus novos alfabetismos, concepções e práticas sobre crianças e as práticas midiáticas por elas desenvolvidas, evidenciando aspectos da cultura participativa e os processos de construção de identidades sociais e culturais, bem como as novas formas de produção e socialização de conhecimentos. Em alguns contextos, a digital divide revela dimensões do acesso e da qualidade dos usos das tecnologias, na escola e fora dela, como sintoma de um fenômeno mais amplo, um gap cada vez maior entre o cotidiano das crianças fora da escola e os sistemas educacionais que transcendem fronteiras e territórios.

A complexa realidade sociocultural nos desafia a pensar o conceito de aprendizagem no contexto da cultura digital para além das redes. Nesse processo, as estratégias para integrar os usos das tecnologias e seus dispositivos na didática têm solicitado um trabalho com competências específicas e novos modelos do processo ensino-aprendizagem. Entre esses modelos, surge o conceito de Episódios de Aprendizagem Situada (EAS), que se origina na reflexão sobre Mobile Learning e nas atividades de microlearning, "um processo de aprendizagem informal relacionado aos fenômenos que atravessam as culturas de mídias atuais, suas fragmentações e recombinações de formatos textuais e transmídiáticos" (RIVOLTELLA, 2013, p.51).

Nessa perspectiva, o conceito de aprendizagem situada se relaciona ao sentido de aprendizagem significativa proposto por Gee (2007) ao analisar as aprendizagens promovidas pelos videogames, esclarece Rivoltella (2016). Ao mencionar o "princípio de significado situado", entre 39 princípios de aprendizagens que considera eficazes, Gee (2007) esclarece que os significados dos signos (palavras, ações, objetos, artefatos, símbolos, textos) estão sempre situados no contexto das experiências "encarnadas", pois, a seu ver, não existem significados gerais ou descontextualizados. Desse modo, a aprendizagem significativa envolve uma relação substancial entre os saberes que já fazem parte do sujeito, ou seja, quando uma nova informação ou prática possibilita uma interação de fato com os conhecimentos anteriores de forma contextualizada e situada. Em síntese, a dimensão situadaquer dizer contextualizada, e o sentido de experiência significativa potencializa as atividades informais, tornando-as ocasião de aprendizagem que pode superar a fragmentação que reveste certas atividades informais. $O$ sentido de aprendizagem significativa envolve a escolha da profundidade mais que a amplitude, pois, ao tratar muitos argumentos num tempo restrito, é quase inevitável obter uma compreensão superficial do conteúdo tratado. jan./abr. 2018 
A metodologia dos EAS também se configura como uma proposta de integração dos dispositivos móveis na didática e fundamenta-se em quatro ideias-chave: o ensino como design, o aprender fazendo, a flipped teaching e a neurodidática, que podem ser assim resumidas (RIVOLTELLA, 2015, p. 14-17): 1. ensino como design e as dimensões do planejamento, da estética e dos conteúdos da cultura na perspectiva das multiliteracies (COPE; KALANTZIS, 2000); 2. aprender fazendo e a perspectiva de um trabalho com laboratórios e seus mediadores para além do espaço da sala de aula, com o entendimento de que a função do pensamento é produzir ações; 3. flipped teaching e a inversão da lógica da didática tradicional de ensino (aula expositiva-tarefas para casa), que se inspira na lição $a$ posteriori (FREINET, 2002), hoje amplamente difundida (MAZUR, 2007); 4. interseção entre neurociências e didática envolvendo o paradigma da simplexidade (BERTHOZ, 2012); o sistema corpo-mente-cérebro, que fundamenta a base da aprendizagem; e os circuitos dos neurônios-espelho, que permitem ressignificar do papel da repetição, da imitação e da experiência.

Ao prever uma estrutura com três momentos em cada aula, a metodologia EAS envolve: 1) momento prévio: um quadro conceitual ou uma situação-estímulo que encaminha uma atividade preparatória aos alunos; 2) momento operativo: uma microatividade de produção em que o aluno deve resolver um problema ou produzir algum conteúdo sobre a situação-estímulo; 3) momento reestruturador: um debriefing sobre o que aconteceu nos momentos anteriores, com retorno aos processos ativados, e sobre os conceitos que emergiram visando à sua reflexão (RIVOLTELLA, 2013, p. 52-53).

Como o trabalho com os EAS implica a produção de artefatos os mais diversos, sejam eles construídos de forma "artesanal" (com lápis, papel, cola, tesoura, etc.) ou digital (com o uso de dispositivos móveis como celular, smartphone, tablet e seus recursos), observa-se que tais possibilidades permitem uma diversidade de expressões, linguagens e suportes. Nesse sentido, a escolha de determinadas propostas também pode revelar certas preferências e/ou estilos de aprendizagem dos estudantes, que por sua vez também demonstram sua familiaridade com certos dispositivos móveis e diferentes níveis de competência no uso educativo de tais ferramentas.

Diversos estudos sobre crianças e tecnologias têm desconstruído a hipótese e o mito dos "nativos e imigrantes digitais" (RIVOLTELLA, 2013; TISSERON, 2016; FANTIN, 2016), pois a chamada 'geração digital' só pode ser compreendida à luz de outras mudanças, das práticas que regulam a vida de crianças e jovens e de seus contextos e ambientes sociais cotidianos (BUCKINGHAM, 2007). Para tais estudiosios, não é possível isolar o componente "tecnologia" e sua capacidade de "produzir efeitos sobre as pessoas" de outros elementos

$\begin{array}{llllll}\text { (C) ETD-Educação Temática Digital } & \text { Campinas, SP } & \text { v.20 } & \text { n.1 } & \text { p. } 66-80 & \text { jan./abr. } 2018\end{array}$


do contexto sociocultural que também interferem nessa relação. Diante disso, é possível tensionar as concepções sobre os "meios" autoalfabetizantes, bem como as possibilidades de aprendizagem na escola com os dispositivos móveis.

Um entendimento ampliado do que sejam os dispositivos móveis -tablet, smartphone, celulares, notebooks, netbooks, palmtops, personal computer (pc)-permite entendê-los como ferramentas culturais que emergem de um sistema multimídia conotado pela personalização, mobilidade, convergência e ubiquidade. Nas práticas culturais de uso, destaca-se a noção de agência das crianças diante das possibilidades que tais dispositivos de aprendizagem oferecem. Entre os usos e as práticas cotidianas de crianças, é possível uma integração de saberes, que atravessam contextos formais e informais, sempre necessitando de mediações.

Diversos mapeamentos sobre os usos dos dispositivos móvies entre crianças demonstram que: nos EUA, mais de $72 \%$ das crianças com até oito anos e $38 \%$ com até dois anos usam dispositivos móveis². Na Alemanhã, $65 \%$ das crianças da escola primária usam tablet e smartphone. Na Itália, $72 \%$ das crianças de oito anos usam smartphone e tablet dos pais, e $38 \%$ das crianças com menos de dois anos já usaram dispositivos móveis para jogar ou assistir a vídeo ${ }^{3}$. A porcentagem de crianças portuguesas que diz acessar a internet diariamente com o uso de smartphone é de $35 \%$, o mesmo valor da Irlanda. "Os valores mais elevados no acesso diário à internet por smartphones provêm da Dinamarca (72\%), Reino Unido (56\%) e Itália (42\%). Atrás de Portugal, encontram-se a Bélgica (28\%) e a Romênia (21\%)."(SIMÕES; PONTE et al., 2014, p.9) ${ }^{4}$. Por sua vez, no Brasil, entre crianças e adolescentes de dez a dezessete anos, o uso de celulares passou de $53 \%$ para $82 \%$; e o uso detablets, de $16 \%$ para $32 \%$, entre 2013 e $2014^{5}$.

Para o estudioso Tisseron (2016), as telas digitais devem ser "domesticadas", no sentido de uma apropriação emancipadora pela criança em conjunto com os adultos. Ele enfatiza as "vantagens e desvantagens" dos usos das telas digitais e das redes sociais em cada idade (3-6-9-12) e, ao destacar a importância da mediação em qualquer idade, sugere uma proposta de uso nos diferentes espaços da educação das crianças.

\footnotetext{
${ }^{2}$ Observatorio Common Sense of Media.Disponível em: https://www.commonsensemedia.org/technologyaddiction-concern-controversy-and-finding-balance-infographic\#. Acesso em: 25 nov. 2017.

${ }^{3}$ Telefono Azzuro. Disponível em:

http://www.azzurro.it/sites/default/files/Materiali/InfoConsigli/Ricerche\%20e\%20indagini/Sintesi IndagineCo noscitivalnfanziaAdolescenza2012.pdf . Acesso em: 25 nov. 2017.

${ }^{4}$ Net children go mobile. Disponível em: https://netchildrengomobile.wordpress.com/ Acesso em: 25 nov. 2017.

${ }^{5}$ Cetic. Disponível em: http://cetic.br/pesquisa/kids-online/ Acesso em: 25 nov. 2017.
}

(C) ETD-Educação Temática Digital Campinas, SP $\quad$ v.20 $\quad$ n.1 $\quad$ p. $66-80 \quad$ jan./abr. 2018


A esse respeito, vale destacar um cenário em que muitas crianças já possuem suas identidades on-line delineadas, por vezes pelos próprios pais, e que o compartilhamento dos dados em rede envolve problemas de privacidade, o que tem levado diversos estudiosos e profissionais que atuam com crianças (professores, pediatras, psicólogos) a buscar formas de sensibilização sobre os direitos das crianças à privacidade, como defende Steinberg (2016). Aliado a isso, também é crescente o número de estudos que colocam em cheque o uso dos dispositivos móveis por crianças na escola, considerando-o como um fator que não apenas favorece mas que também pode prejudicar a aprendizagem (TISSERON, 2016).

No debate sobre o uso/proibição do celular em sala de aula, diversas pesquisas demonstram, apesar das divergências de abordagem a respeito, que o uso do celular aumenta a falta de concentração e que nem sempre seu uso repercute na melhoria da aprendizagem (BELAND; MURPHY, 2015). Embora não haja consenso entre os estudiosos da area sobre o potencial pedagógico de tal artefato no Ensino Fundamental e Ensino Médio, é importante problematizar certos usos de celular/smartphone em contextos formativos e promover uma reflexão a respeito na perspectiva da mídia-educação. Como por exemplo: desnaturalizar a pesquisa na internet durante a aula, de modo a refletir sobre os caminhos de busca, a seleção e diversidade de fontes, a confiabilidade da informação; esclarecer sobre os usos para registro fotográfico e/ou audivosual e os devidos cuidados ao contemplar o consentimento das pessoas envolvidas; chamar a atenção para o uso responsável, sobretudo diante do compartilhamento de conteúdos em redes. Desse modo, metodologias que potencializem o uso educativo dos dispositivos móveis no contexto da cultura digital podem atuar na mediação das aprendizagens das crianças na escola, que foi um dos recortes da pesquisa (FANTIN, 2015c).

\section{A PESQUISA}

A reflexão deste artigo parte da pesquisa "Multiletramentos e aprendizagens formais e informais: possíveis diálogos entre contextos escolares e culturais" ${ }^{6}$,coordenada pela autora, que se constituiu em uma "pesquisa guarda-chuva" e envolveu diversos projetos e pesquisas correlatas ao tema, os quais foram desenvolvidos em parceria com graduandos, mestrandos e doutorandos ${ }^{7}$. De abordagem qualitativa, na perspectiva metodológica da Bricolagem (KINCHELOE, 2001), na intersecção dos estudos da mídia-educação, da cultura infanto-juvenil e da didática, construímos um diálogo sobre e com crianças e tecnologias em diferentes contextos socioculturais, mediados pela metodologia EAS (RIVOLTELLA, 2013;

\footnotetext{
${ }^{6}$ O Projeto contou com financiamento do CNPq, obtidopela participação no Edital MCTI/CNPq/MEC/CAPES Chamada no 43/2013 - Ciências Humanas Sociais e Sociais Aplicadas (processo no 409142/2013-1).

${ }^{7}$ LyanaThediga de Miranda, Karin Orofino, Juliana Muller (doutorado), Gabriela Cavicchioli, Bárbara Malcut (mestrado), Franciely Rosa (Iniciação Científica).
} 
FANTIN, 2015). A investigação foi desenvolvida entre 2014/2015, e o campo empírico da pesquisa mais ampla envolveu duzentos estudantes do Ensino Fundamental de duas escolas públicas de Florianópolis, SC/Brasil, quarenta professores de diversas escolas do município e oitenta estudantes de três turmas de um Curso de Pedagogia. O recorte dessa reflexão que atravessa a pesquisa "guarda-chuva" refere-se às práticas culturais de estudantes do Ensino Fundamental com idade entre nove e doze/treze anos, com destaque para as aprendizagens formais e informais e, particularmente, para as estratégias de aprendizagem learning by doing observadas nas diferentes turmas a partir das propostas desenvolvidas com os estudantes nas escolas.

O desenho da pesquisa mais ampla pode ser assim resumido: num primeiro momento, realizamos a aproximação com uma Comunidade de Práticas de professores italianos que adotam a metodologia EAS, na qual acompanhamos momentos de formação, experiências didáticas nas escolas e entrevistamos professores. Num segundo momento, realizamos a pesquisa empírica em duas escolas públicas de Florianópolis, com seis turmas de alunos entre sete e quinze anos, envolvendo cerca de duzentos estudantes. Tal percurso na escola envolveu observação,pesquisa-formação com professores das turmas participantes, intervenção didática com aplicação da metodologia EAS, entrevistas e grupos focais com estudantes. No terceiro momento, propusemos um Curso-Piloto de Formação para Professores voltado aos docentes interessados em conhecer a metodologia EAS. Após análise parcial dos dados, realizamos um Seminário de Socialização da Pesquisa, para compartilhar e discutir as experiências, que contou com a participação dos professores cursistas (FANTIN, 2015c). Nesse artigo, o recorte se refere às propostas de intervenção didática desenvolvidas com estudantes entre nove e doze/treze anos das duas escolas participantes da pesquisa, conforme foco anunciado acima.

Importante ressaltar que, nas intervenções didáticas com os EAS, consideramos os quatro componentes da Pedagogy Literacy (COPE;KALANTZIS, 2000): a prática situada (experiências baseadas na construção de significado na esfera da vida privada e pública, assim como na escola), o ensino aberto (atividades desenvolvidas como metalinguagem de design), a abordagem crítica (reflexão e relações entre o contexto social e os significados das atividades) e a prática transformada (alunos produtores de sentidos).

A seguir, apresenta-se a narrativa de algumas situações da pesquisa que evidenciam aspectos das aprendizagens situadas com o foco na estratégia learning by doing, aprender fazendo com base nas aprendizagens formais e informais evidenciadas na pesquisa. 


\section{CRIANÇAS E SUAS APRENDIZAGENS FORMAIS E INFORMAIS}

Durante uma oficina de produção de capa artesanal do caderno de registros das crianças de uma turma do $5^{\circ}$ Ano, entre as atividades do momento operatório do EAS, uma criança desenhou um cemitério com a frase: "Get over "hear' [sict". Perguntei se ela sabia o significado da frase, e ela respondeu: "Venha já para cá". Continuei a conversa sobre como ela aprendeu a língua inglesa, e ela disse: "No jogo Mortal Combat [...]No jogo a gente ouve o áudio em inglês e lê a legenda em português" (FANTIN, 2015c).

Tal depoimento expressa um aspecto da aprendizagem informal que as crianças constroem durante as situações de jogo, no caso, a aprendizagem da língua inglesa com o videogame, referendando a análise de outras pesquisas em que observamos tal aspecto (FANTIN,2015a, 2015b). Identificar e trazer para a sala de aula tais aprendizagens pode ser uma ocasião de valorizar tais saberes, sistematizá-los e enriquecê-los, como por exemplo, ampliar a lógica de aprendizagem no jogo para outros contextos, como propõe Gee (2007).

Em uma oficina de stopmotion realizada com uma turma do 6을 Ano, na atividade de edição de vídeo com o aplicativo pic pac, no momento operativo do EAS o grupo deveria baixar a música para a trilha sonora da produção audiovisual. Comoum menino usava o referido aplicativo com grande desenvoltura, perguntei se ele já o conhecia e, na continuidade da resposta afirmativa sobre como aprendeu, ele disse: "Vendo as pessoas usarem na minha casa." (FANTIN, 2015c).

Tal situação pode ser analisada a partir de diversos olhares. Na relação entre aprendizagem formal e informal, destacamos a competência midiática, demonstrada em seu sentido mais técnico, construída informalmente pelo menino em contexto doméstico, ao ver outras pessoas usarem o aplicativo. Na dimensão de acesso, que revela o sentido de pertencimento, tal saber também pode se tornar ponto de partida para outras aprendizagens e competências sociais e relacionais (GOLLEMAN, 2006), como vimos quando solicitamos a ele que ensinasse seus colegas a baixarem a música, numa atividade que se tornou colaborativa. Também evidenciamos a interatividade que o aplicativo promoveu pela experiência direta no ambiente (CARBONI, 2015), além de enfatizar a resolução colaborativa de problemas (MIRANDA, 2015).

Em outra turma do 60 Ano, em diversos momentos com que trabalhamos com vídeoestímulo, nas etapas preparatórias dos EAS os estudantes manifestaram interesses por certos vídeos e solicitaram o link para rever em suas casas. No momento subsequente, operatório, eles compartilharam suas inquietações evidenciando a relação do formalinformal como continuidade de práticas cotidianas, linguagens e conhecimentos, além de demonstrarem habilidades técnicas, competências midiáticas e novos letramentos, como

$\begin{array}{llllll}\text { (C) ETD-Educação Temática Digital } & \text { Campinas, SP } & \text { v.20 } & \text { n.1 } & \text { p. } 66-80 & \text { jan./abr. } 2018\end{array}$


podemos observar no relato: "Quando sugerimos um canal do Instagram para inspiração na elaboração do vídeo, em que alguns já acessaram pelo celular instantaneamente, demonstrando determinadas competências [...], alguns pediram para escrever no quadro, para que pudessem buscar a informação em outros momentos, e alguns perguntaram se podiam mostrar para as famílias." (CAVICCHIOLI, 2015, p. 99).

Durante as entrevistas realizadas com alguns estudantes, também foi possível observar a relação das múltiplas linguagens, competências e novos letramentos transitando entre formal e informal. Embora possa ser considerado um "caso a parte", o depoimento do estudante P.(treze anos) sobre suas experiências com uso de tecnologias dentro e fora da escola revela diversas faces de tais relações, visto que ele frequentava um curso extracurricular e também participava de uma pesquisa na área de Design para construção de jogos eletrônicos: "Aprendi a maioria das coisas em casa, né, porque, infelizmente, hoje, o Brasil é muito carente em ensinamentos com tecnologias, didáticas com tecnologias [...] lá na UFSC [Universidade Federal de Santa Catarina] eles têm projetos de ensinar com jogos [...] e têm cursos gratuitos, como um que estou fazendo de Design [...]. Quando eu tinha cinco anos, minhas irmãs ganharam um computador bem singelo, não era potente [...] comecei a mexer ali [...] e ficava me perguntando como que ocorrem os processos dos jogos, até que comecei a fazer os cursos que comentei [...]. O UCA [projeto Um Computador por Aluno] foi um projeto muito importante pra mim e para algumas pessoas, porque, por mais que o pessoal usasse mais pra jogar, eles já estavam tendo contato com um computador, e tendo contato com um computador já vai saber mexer no próximo que tu vê, entende?[...] uma oportunidade, quando estava conectado à internet, podia baixar vários jogos, e isso foi o que o pessoal mais aprendeu, sabe? [...] a gente também fez muita pesquisa *...+"(CAVICCHIOLI, 2015, p.102).

A singularidade do depoimento acima revela interesses e motivações pessoais diversas, assim como as competências técnicas, midiáticas, comunicativas e relacionais construídas nesse movimento formal-informal. Vale destacar que o aluno foi convidado a participar do referido curso em razão de seu desempenho na escola, sobretudo no âmbito dos usos das tecnologias propiciadas pelo Projeto UCA. Aliás, nas análises das práticas culturais de crianças no contexto do referido projeto, em pesquisa anterior, constatamos essa dimensão entre formal e informal também como possibilidade de pertencimento e diálogo entre família a escola (FANTIN, 2015a).

$\mathrm{Na}$ relação entre aprendizagens formais e informais, observamos diversas articulações entre linguagens e competências que sugerem diferentes possibilidades de apropriação de conhecimentos construídos em práticas e eventos de novos letramentos (LANKSHEAR;KNOBEL, 2011). Nos EAS também identificamos relações entre saberes formais e informais expressos na linguagem escrita (registros de atividades e pesquisas solicitadas,

\begin{tabular}{|c|c|c|c|c|c|}
\hline (C) ETD-Educação Temática Digital & Campinas, SP & v.20 & n.1 & p. $66-80$ & 2018 \\
\hline
\end{tabular}


elaboração de roteiro, sinopses e outras narrativas), na linguagem corporal (gestos, expressões, performances e simulações de personagens durante a produção audiovisual), na linguagem oral (argumentos, discussão e socialização das produções) e em outras expressões artísticas (desenhos de storyboard, fotografias, modelagem e construções lúdicas). A metodologia EAS propiciou diversas situações e contextos que deram visibilidade aos saberes prévios das aprendizagens informais nos eventos de letramentos e aos saberes sistematizados nas aprendizagens formais das produções audiovisuais (filmar, editar, compartilhar o material em repositórios digitais), saberes refletidos e problematizados do ponto de vista da educação.

\section{DISPOSITIVOS MÓVEIS E OS DESAFIOS DA MEDIAÇÃO EDUCATIVA}

A partir das narrativas acima, destacamos algumas considerações sobre os usos dos dispositivos móveis na escola, de modo a destacar possíveis limites e possibilidades do foco nas aprendizagens formais e informais a partir da estratégia learning by doing,aprender fazendo, observadas durante a pesquisa.

Vimos que as aprendizagens a partir da experiência, da prática, da observação, da simulação e da representação envolvem uma perspectiva da aprendizagem por aquisição, por pesquisa, por prática de colaboração, discussão e reflexão. Nas propostas de EAS evidenciadas na pesquisa, identificamos tais ações e práticas dos estudantes quando desenvolviam atividades e tarefas solicitadas, escutavam, liam e compreendiam diferentes textos (no momento preparatório), quando produziam e compartilhavam seus artefatos, como roteiros, storyboards, fotografias e animações (no momento operatório), e quando os analisavam criticamente, desenvolvendo reflexões sobre os processos ativados, bem como sobre os riscos e as possibilidades de compartilhar as produções em rede (no momento reestruturador), sempre a partir de nossa mediação, como sugere a metodologia EAS. Tais processos evidenciaram também aspectos do learningbydoing que emergiam sobretudo a partir de lógicas didáticas e estratégias de aprendizagem como a Resolução de Problemas, o Aprender Fazendo e a Reflexão sobre as dimensões éticas e estéticas do que foi produzido. A esse respeito, eis as oficinas propostas aos estudantes para operacionalizar tais práticas: oficina para confeccionar um caderno de registros; oficina de fotografia; oficina de roteiro; oficina de produção de audiovisual; oficina de edição e outras. Entre alguns limites presentes em tais atividades, observamos: a reprodução mais que a criação de conteúdos; a repetição de práticas de consumos televisivos e das redes sociais no uso de clichês em diferentes produções audiovisuais; a difícil negociação de interesses que emergiam no momento de operar certos conceitos, durante as atividades colaborativas, necessitando sempre de mediações. 
Nos EAS, além das motivações diferenciadas entre os estudantes, observamos que os dispositivos móveis podem representar elementos de continuidade entre experiências cotidianas e âmbitos escolares em seu sentido afirmativo. A personalização facilita o desenvolvimento de novas modalidades de aprendizagem fora da escola em diálogo com o currículo a partir de aspectos da informalidade, visto que os dispositivos também se configuram em um instrumento para transmitir conteúdos específicos e desenvolver competências em diversos âmbitos (leitura, escrita e outras atividades de produção). A manipulação direta de conteúdos, confluindo percepções e ações ao mesmo tempo, na tela e em interação, pode ser um momento-chave da experiência de jogo e aprendizagem, além das dimensões emocional, social, cognitiva e metacognitiva ali envolvidas.

Por outro lado, o uso de dispositivos móveis pelos estudantes nos EAS também evidenciou elementos de descontinuidade entre os âmbitos formais e informais, que podem ser entendidos como limites observados na pesquisa. Por exemplo, em diversas práticas midiáticas dos estudantes na escola, observamos a homologação dos usos dos dispositivos móveis no cotidiano informal sem a reflexão desejada. Além disso, grande parte das produções midiáticas das crianças segue modelos provindos da indústria cultural, sem questionar seus padrões. Isso demonstra não apenas as diferenças de capital cultural, mas a importância de se criar - na escola - possibilidades para ampliar os repertórios dos estudantes a partir de outros referenciais, pois tais experiências se referem a uma perspectiva de multiletramentos que não seja apenas instrumental, mas sobretudo cultural. Outro limite observado se refere à relação processo-produto e às representações de professores e estudantes sobre as produções realizadas na escola. Ainda que consideremos a importância do processo e da riqueza de aprendizagens que proporciona, o produto também pode ser expressão desse percurso. Ou seja, a criança nem sempre se reconhece em suas produções e nem sempre o resultado final é satisfatório do ponto de vista éticoestético, a partir do olhar de professores e estudantes. Nesse sentido, o momento reestruturador da metodologia EAS pode assegurar tal reflexão: o quê e o quanto as crianças aprenderam, se ficaram satisfeitas com suas produções, o que poderia ser melhorado, etc. É neste momento que o professor pode oportunizar o pensar sobre a intenção inicial da proposta, o percurso desenvolvido durante o trabalho e o que foi feito e aprendido. Ao relacionarem-se as produções feitas, individualmente ou em grupo, também se pôde evidenciar a diversidade presente em tais produções, a relação de troca que assegura a aprendizagem em pares e o aprender fazendo e refletindo. Ressaltamos que as práticas midiáticas das crianças com dispositivos móveis fora da escola constituem a base para ancorar e contextualizar as novas experiências, e, quando articuladas às propostas mídia-educativas, podem desencadear aprendizagens significativas e deslocar os protagonismos dos dispositivos em busca de novas possibilidades de autoria infantil, tal como vimos em algumas narrativas. 
As potencialidades e os riscos dos dispositivos móveis evidenciados na pesquisa concordam com estudos de Tisseron (2016) e Rivoltella (2016) sobre o tema. Para esses autores, o interesse não é discutir o que as mídias fazem com as crianças ou o que as crianças fazem com as mídias, mas o que acontece nesse "meio", com um olhar que vai além da simplificação e renuncia às tentações de "idealizar ou demonizar" as tecnologias, reafirmando a importância de professores e educadores em geral conhecerem as mídias e seus dispositivos, para que possam discutir com as crianças, ensinando-as a distinguirem contextos e situações. Nesse sentido, observamos que processos de aprendizagem mais abertos significam processos espontâneos , assistemáticos e atualizados ao sabor das circunstâncias e de curiosidades contingentes , e, como a escola se baseia na aprendizagem formal, há que lidar com a tensão da cultura do divertimento e da comunicação superficial que os dispositivos também englobam. Além disso, ponderamos que a conexão em rede dos dispositivos móveis desestabiliza as formas tradicionais de aprendizagem escolar, impondo novas formas de apropriação nesse espaço e interseções entre vida cotidiana, internet eescola. Assim, o que apontamos como riscos pode ser entendido como um aspecto central do trabalho com os dispositivos móveis, não apenas por criar condições de subverter os modus operandi do aprender mas também por possibilitar outras percepções sobre as aprendizagens desencadeadas na confluência dessas práticas nos diferentes espaços formais e informais - e suas singularidades.

No entanto, embora haja um aumento crescente de pesquisas sobre a temática, ainda não temos dados suficientes para saber ao certo as consequências dos diferentes tipos de uso dos dispositivos móveis. Pesquisas evidenciam que: o uso inadequado pode atuar negativamente sobre o desenvolvimento infantil (excesso de estímulo visual/auditivo, problemas posturais e de movimento corporal, assim como obesidade); o excesso de uso pode comprometer certos tipos de atenção das crianças; certas práticas com dispositivos móveis potencializam o bulismo e podem induzir comportamentos de isolamento e/ou exposições suspeitas em redes. Nesse sentido, enfatizamos a necessidade de empoderamento de crianças e jovens diante dos dispositivos móveis, o que, segundo Boyd (2017), está longe das competências midiáticas mínimas.

Por ser parte de um sistema de consumo que aumenta a cada dia, a falta de mediação e reflexão sobre uso sustentável dos dispositivos móveis também pode estimular o consumismo. Para minimizar tais aspectos, as mediações educativas são fundamentais, tanto para negociar com as crianças, conhecer o que fazem e apreciam como para combinar os tempos de uso, a escolha de jogos e app, bem como as diversas formas de participação nas redes sociais, sempre assegurando os direitos de proteção, provisão e participação.

Por fim, enfatizamos mais uma vez que a atenção não é à tecnologia, mas sim às crianças e às suas relações, linguagens e formas de expressão. As narrativas, os jogos, os

\begin{tabular}{|c|c|c|c|c|}
\hline (C) ETD-Educação Temática Digital & Campinas, SP & v. 20 & n.1 & jan./abr. 2018 \\
\hline
\end{tabular}


consumos midiáticos e outras práticas também demonstram como as crianças aprendem com os dispositivos. E, levando isso em consideração, enfatizamos a pluralidade de possibilidades sensoriais no uso de artefatos e as diferentes formas de autoria e expressão da criança na escola, como por exemplo, por meio de fotografias, textos, desenhos, maquetes, entrevistas, flipbooks, stopmotion e muitos outros. Com crianças maiores, destacamos as narrativas em múltiplas linguagens, digital storytelling, produção audivisual e animação.

Nas diferentes produções autorais, a mediação educativa ocorre com o propósito de trabalhar a dimensão crítica, reflexiva, lúdica e poética das autorias infantis, com especial atenção à memória e aos saberes locais dos diferentes grupos, bem como às interações, aos pertencimentos e às formas de participação social das crianças. Nesse movimento, a dimensão da corporeidadepermite compreender a criança em seu agir, pensar e sentir, tendo o corpo como veículo entre mente, cultura, afeto e sociabilidade. Por fim, tendo em vista o desafio da mediação educativaque problematiza a diversidade de práticas culturais, as formas de consumo, o repertório provindo das mídias e da cultura digital, consideramos os EAS como uma possibilidade diferenciada de articular tanto suas relações entre os saberes prévios das crianças e seu o imaginário infantil como as dimensões social, cultural, cognitiva e afetiva, aprendizagens que as crianças constroem em constante devir.

\section{REFERÊNCIAS}

BELLAND, Louis-Philippe ; MURPHY, Richard. Technology, distraction\& student

performance. London: Centre for Economic Performance, 2015.

BERTHOZ, Alain. La Semplesssità. Torino: Codice, 2012.

BOYD, Danah. It's complicated.The social lives of networked teens. London: Yale University, 2014.

BUCKINGHAM, David. (Ed.) Youth, Identity and Digital Media. Cambridge: MIT Press, 2007.

CARBOTTI, Silvia. App per l'infanzia: linee guida per una progettazione efficace. Form@re, Firenze, v. 15, n. 1, p. 159-169, 2015.

CAVICCHIOLI, Gabriela Spagnuolo. Competências audiovisuais e os novos letramentos na escola. 2015. 202f. Dissertação (Mestrado em Educação) - Universidade Federal de Santa Catarina, Florianópolis, 2015.

COPE, Bill; KALANTZIS, Mary (Ed.).Multiliteracies: literacy learning and the design of social futures. New York: Routledge, 2000.

EUGENI, Ruggero. Nativi posmediali: alcuni compiti educativi dell'istruizone scolastica. OPPInformazioni, Milano, v. 42, n. 118, p. 22-29, jan./ago. 2015.

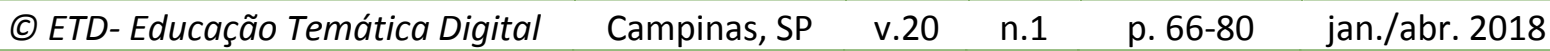


FANTIN, Monica. Perspectives on Media Literacy, Digital Literacy and Information Literacy.International Journal of Digital Literacy and Digital Competence, Cassino, v. 1 n. 4, p. 10-15, out./dez. 2010.

FANTIN, Monica. Novos Paradigmas da Didatica e a Proposta Metodológica dos Episódios de Aprendizagem Situada, EAS. Educação \&Realidade, Porto Alegre, v. 40, n. 2, p.443-464, abr./jun. 2015. Disponível em:

http://seer.ufrgs.br/index.php/educacaoerealidade/article/view/46056/33409 . Acesso em: 25 nov. 2016.

FANTIN, Monica. Estudantes e laptop na escola; práticas e diálogos possíveis. In: QUARTIERO, Elisa Maria; BONILLA, Maria Helena Silveira; FANTIN, Monica (Orgs.) Projeto UCA:entusiasmos e encantamentos de uma política pública. Salvador: Edufba, 2015a. p. 187-238.

FANTIN, Monica. Crianças e games na escola: entre paisagens e práticas. Revista Latinoamericana de Ciencias Sociales, Niñez y Juventud, Manizales, v. 13, n. 1, p. 195-208, jan./jun. 2015b. Disponível em:

http://revistalatinoamericanaumanizales.cinde.org.co/?page id=4252 Acesso em: 25 nov. 2016.

FANTIN, Monica. Aproximações aos EAS: aprendizagens, dispositivos móveis e multiliteracies na formação de crianças, jovens e professores.SEMINÁRIO DE PESQUISA EM MÍDIA-EDUCAÇÃO, 5.SEMINÁRIO MULTIDEAS, 1. Florianópolis, 9 e 10 dez. 2015. Anais... Florianópolis: UFSC, 2015c. p. 10.

FANTIN, Monica. Nativos e imigrantes digitais em questão: crianças e competências midiáticas na escola. Passagens, Fortaleza,v. 7, n. 1, p. 5-26, 2016. Disponível em: http://www.periodicos.ufc.br/passagens/article/view/3652/3279 Acesso em: 25 mar. 2017.

FREINET, Celestin. La Scuola del Fare.Bergamo: Junior, 2002.

KINCHELOE, Joe. Describing the Bricolage: Conceptualizing a New Rigor in Qualitative Research.Qualitative Inquiry, [S.I], v. 7, n. 6, p. 679-692, 2001.

GARDNER, Howard; DAVIS, Katie. Generazione App. Milano: Feltrinelli, 2013.

GEE, James Paul. What videogames have to teach us about learning and literacy.New York: Palgrave MacMillan, 2007.

GOLEMAN, David. Inteligência Social. Rio de Janeiro: Elsevier, 2006.

LANKSHEAR, Colin; KNOBEL, Michele. Nuevos alfabetismos.Su práctica cotidiana y el aprendizaje en el aula.3. ed. Madrid: Ediciones Morata, 2011.

MAZUR, Erick. Peer Instruction:getting students to think in class. New York: American Institute of Pysics, 2007.

MIRANDA, Lyana T. Aproximações com a metodologia EAS no 6ㅇ Ano. In: SEMINÁRIO DE

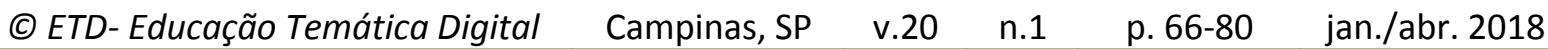


PESQUISA EM MÍDIA-EDUCAÇÃO, 5. SEMINÁRIO MULTIDEAS, 1.Florianópolis, 9 e $10 \mathrm{dez}$. 2015. Anais... Florianópolis: UFSC, 2015. p. 22-29.

MIRANDA, Lyana; FANTIN, Monica. A singularidade na multiplicidade: crianças e tecnologias móveis na escola no contexto da cultura digital. Revista Tempos e Espaços em

Educação,São Cristóvão,v. 8, n. 17, p. 85-97, set./dez. 2015. Disponível em: http://www.seer.ufs.br/index.php/revtee/article/view/4516/3712 . Acesso em: 25 nov. 2016.

MULLER, Juliana. Aproximações com a metodologia EAS no 5 Ano. In: SEMINÁRIO DE PESQUISA EM MÍDIA-EDUCAÇÃO, 5. SEMINÁRIO MULTIDEAS, 1. Florianópolis, 9 e 10 dez. 2015. Anais... Florianópolis: UFSC, 2015. p. 30-36.

RIVOLTELLA, Pier Cesare. Fare Didattica con gli EAS.Episodi di Apprendimento Situati. Brescia: La Scuola, 2013.

RIVOLTELLA, Pier Cesare. Che cos'è un EAS:L'idea, il metodo, la didattica. Brescia: La Scuola, 2016.

SARMENTO, Manuel; PINTO, Manuel. As crianças: contextos e identidades. Braga: Centro de Estudos da Criança. Braga: Universidade do Minho,1997.

STEINBERG, Stacey, B. Sharenting: Children's Privacy in the Age of Social Media.

Forthcoming, Emory Law Journal, [S.I], Series Paper n. 16-41, p. 839-884, 7 jan. 2016

Disponível em: Document2 https://papers.ssrn.com/sol3/papers2.cfm?abstract id=2711442 Acesso em: 15 fev. 2017.

TISSERON, Serge. 3-6-9-12 Diventare grande all'epoca degli schermi digitali. Brescia: La Scuola, 2016.

\section{Agradecimentos}

Agradeço ao CNPq pelo financiamento da pesquisa que possibilitou as reflexões contidas nesse texto.

'Revisão sob a responsabilidade de : John Mafra

E-mail: trabalho.academico.bnu@gmail.com 